\title{
Phytochemical and Quality Assessment of Acacia nilotica Linn and Acacia leucophloea willd Flowers
}

\author{
Raju Ilavarasan, Leela Vadivelu*
}

\section{Raju llavarasan, Leela Vadivelu*}

Captain Srinivasa Murti Drug Research Institute for Ayurveda and Siddha (CCRAS), Arumbakkam, Chennai-106, Tamil Nadu, INDIA.

\section{Correspondence}

Raju llavarasan, Captain Srinivasa Murti Drug Research Institute for Ayurveda and Siddha (CCRAS), Arumbakkam, Chennai-106, Tamil Nadu, INDIA

Phone no: 09444873211

E-mail: arilavarasan@yahoo.co.in

\section{History}

- Submission Date: 24-03-2017

- Review completed: 12-06-2017;

- Accepted Date: 09-08-2017

DOI : 10.5530/pj.2017.6.113

Article Available online http://www.phcogj.com/v9/i6

\section{Copyright}

() 2017 Phcog.Net. This is an openaccess article distributed under the terms of the Creative Commons Attribution 4.0 International license.

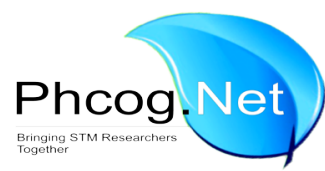

\begin{abstract}
Objective: The quality criteria for herbal drugs are based on a clear scientific definition of the raw material. Even though global herbal resources have a great potential as natural drugs and are of great commercial importance, they are very often procured and processed without any scientific evaluation, and launched onto the market without any mandatory safety and toxicology studies. On that basis, an attempt was made on a well-known herbal drug A.nilotica flower and A.leucophloea flower by evaluation of phytochemical and toxicological parameters like heavy metals, aflatoxins, total microbial load and pesticide residues. Method: The procedures recommended in AOAC, ASTA were followed to determine analysis of heavy metals, aflatoxins, microbial load and pesticide residues. Thin layer chromatographic technique was used to separate the chemical compounds present in the drug. Result and Conclusion: Results obtained during this experiment revealed that heavy metals, aflatoxins, total microbial load and pesticidal residues were variable but found within the prescribed limits. Phytochemical evaluation revealed that the catechin phytoconstituents is absent in A.leucophloea flowers when compared with A.nilotica flowers. Hence, there is an urgent need for mandatory evaluation of these parameters in every crude drug before further processing to ensure safety and efficacy of Indian medicinal plants for better acceptance at International platform. The study revealed specific identities for the particular crude drug which will be useful in identification and control to adulterations of the raw drug.
\end{abstract}

Key words: A. leucophloea, A. nilotica flowers, Phytochemical, TLC and Catechin

\section{INTRODUCTION}

Herbal medicines have been used in medical practice for thousands of years and recognized especially as a valuable and readily available resource for health care. Traditional herbs and herbal products have been considered to be mild, non-toxic and even harmless because of their natural origin. Like other crops, medicinal plants are susceptible to insects and diseases both in the field and the storage, so pesticides are widely used for their protection. In fact, contamination of crude medicinal plants as well as their products has increasingly been reported. ${ }^{1,2}$ This has brought concerns and fears regarding practitioner's professionalism and quality, efficacy and safety of their treatment methods and also for the products from herbal and natural sources available in market. Because of the high cost of pesticide' free cultivation, organic cultivation is only possible on a small scale and wild raw material is of insufficient quantity to meet the needs to the herbal drug market. The ever increasing consumption of medicinal plants necessitates large scale cultivation of medicinal plants which is not possible without use of pesticides. Attentions usually focused on contamination by organochlorine pesticides (OCPs) due to their toxicity and persistence in environment and contamination by common pesticides. ${ }^{3,4}$
Similarly, aflatoxins (AFs) are secondary metabolites produced by fungi Aspergillus, particularly flavus and parasiticus. ${ }^{5}$ There are four naturally occurring AFs, designated B1,B2, G1 and G2 with AFB1 the most common and toxic. The carcinogenic, mutagenic and immuno-suppressive effects of aflatoxins on several animals have been fully documented. ${ }^{6}$ Human liver cancer and levels of aflatoxins in the daily diet are strictly correlated as epidemiological studies. ${ }^{7}$ Furthermore, previous works show that aflatoxins levels are not reduced by domestic cooking with either microwave or conventional gas oven heating $^{8}$ and that AFs do not decompose at the temperature of boiling water during the preparation of the drink. ${ }^{9}$ It is therefore important to have a simple and quantitative method of analysis to control levels of aflatoxins in food. In 2002 European Regulatory sets maximum limits for spices (Capsicum spp., Piper spp., Myristica fragrans, Zingiber officinale, Curcuma longa) (AFB15 g/kg; total AFs $10 \mathrm{~g} / \mathrm{kg})(02 / 472 / \mathrm{EC})$. It is therefore imperative to ensure quality of the preparations derived from the traditional plants by using modern techniques and applying suitable standards. 
Standardization of raw drugs in herbal industry is an important step towards quality control. Several analytical parameters such as physicochemical constants, estimation of elements, heavy metals, microbial contamination, aflatoxins and pesticide residue are to be carried out as a measure of quality check. The World Health Organization ${ }^{10}$ emphasized certain quality standards and has proposed certain guidelines for the assessment and development of standard herbal products.

Acacia nilotica and Acacia leucophloea belongs to the family Leguminosae. It is a moderate sized tree much fissured, spines long, straight white, sharply prickled. A. nilotica flowers are yellow, fragrant in axillary and with globule heads. A. leucophloea flowers are creamy yellow, fragrant in axillary and with globule heads. ${ }^{11}$ The ethno medical information states that, the parts of the tree find use in diabetes, skin diseases and leucorrhoea. These are also used as an antidiarrheal, antidysenteric, antidiabetic. The stem bark is an astringent, ${ }^{12-17}$ used in ulcers and wound healing ${ }^{18,19}$ as an antidote to snake bite, ${ }^{20}$ in dysentery ${ }^{21}$ and for tooth ache. ${ }^{22}$ In the present paper an attempt was made for analysis of heavy metals pesticide residues, aflatoxins, microbial load and phytochemical assessment of A.nilotica and A.leucophloea flowers.

\section{MATERIALS AND METHOD}

The fresh flowers of A.nilotica Linn, A.leucophloea Willd were collected from various domestic places in Thanjavur district, Tamilnadu, India, in the month of August 2009. The flowers were identified by Taxonomist, and authenticated by Prof.P.Jayaraman, Botanist, Director, Plant Anatomy Research Centre, Tambaram, Chennai, India. A voucher specimen number was PARC/2009/2093 and PARC/2009/2094 and it was deposited in CSMDRIA at Chennai for the future reference.

\section{Reagent and Materials}

Standard catechin, aflatoxins, was purchased from M/s Sigma chemicals. Aluminum plates precoated with silica gel $60 \mathrm{~F}_{254}$ of $0.2 \mathrm{~mm}$ thickness (E. Merck, Darmstadt, Germany) were used without pretreatment. All chemicals and solvents used were analytical and HPLC grade (E.Merck, Mumbai, India).

The procedures recommended in $\mathrm{AOAC}^{23}$ were followed to determine analysis of heavy metals, aflatoxins and pesticide residues. The powdered samples were weighed (each $1 \mathrm{~g}$ ) into separate conical flasks and treated with $5 \mathrm{~mL}$ of concentrated nitric acid. The flasks were covered with watch glasses and heated for an hour; the contents of the flasks were treated with additional $5 \mathrm{~mL}$ of nitric acid, followed by $2 \mathrm{~mL}$ of $30 \%$ hydrogen peroxide solution. The heating was continued till the clear solution was obtained. The mixture was diluted with deionized water and filtered through Whatman No. 42 filter paper and the solutions were made up to $50 \mathrm{ml}^{24}$

Aflatoxins were determined by Kobra cell technique using Agilent HPLC instrument as per the method ASTA. ${ }^{25}$ Pesticide residues were analyzed using GC-MS Agilent instrument equipped with mass selective detector as per the method AOAC. ${ }^{23}$

For determination of microbial load, $1 \mathrm{~g}$ of each sample was weighed accurately in separate flasks and $99 \mathrm{ml}$ of sterile distilled water was added. The samples in the flask were kept in a mechanical shaker for few minutes to obtain uniform suspension of microorganisms. The dilution is $1: 100$ or $10^{-2}$ from, which $1 \mathrm{ml}$ was transferred to $9 \mathrm{ml}$ of sterilized distilled water to make a 1:1000 dilution and this procedure was repeated up to 10-6 dilution. Each $0.1 \mathrm{ml}$ of serially diluted sample was inoculated to the sterile plates containing nutrient agar, SS agar and potato dextrose agar (PDA) by spread plate method.

Nutrient agar and SS agar plates were incubated at $37^{\circ} \mathrm{C}$ for 24 hour and PDA plates were incubated at room temperature for 3-5 days. Bacterial and fungal colonies were counted using a colony counter. ${ }^{26}$

Thin layer chromatographic technique was used to separate the chemical compounds present in the drug. Various solvent systems were checked to separate the maximum number of chemical compounds in the drug. TLC of the methanolic extract developed in the mobile phase of Chloroform:Methanol (8:2 v/v). After air drying the plate was not visualized in UV 254 and $366 \mathrm{~nm}$. The plate was then dipped in Vanillin -Sulphuric acid and heated in hot air oven at $105^{\circ} \mathrm{C}$ till the spots appeared.

\section{RESULT AND DISCUSSION}

The contents of heavy metals namely lead, mercury, cadmium and arsenic are found to be within the permissible limit ${ }^{27}$ for the A.nilotica and A.leucophloea, indicating that the flowers are safe to utilize as drugs (Table 1). The report for analysis of aflatoxins in the A.nilotica and A.leucophloea is given in the Table 3. The aflatoxins B1,B2, G1 and G2 were below the detecting level revealing that they are free from toxins and are safe for internal use. Further the studies indicated that the absence of these aflatoxins would help to increase in shelf life of the raw drug. The various pesticide residues such as $\alpha, \beta, \gamma, \delta$-hexachlorocyclohexane $(\alpha, \beta, \gamma, \delta$-HCH), o,p'-dichlorodiphenyl trichloroethane (o,p-DDT), p,p'dichlorodiphenyltrichloroethane (p,p'-DDT), o,p-dichlorodiphenyl dichloroethylene (o,p-DDD), p,p-dichlorodiphenyldichloroethylene (p,p-DDD), $\alpha$-endosulphan, $\beta$ - endosulphan, o,pdichlorodiphenyldich loroethane (o,p-DDE) and p,p'-dichlorodiphenyldichloroethane (p,pDDE) are analyzed. None of the above pesticides is detected (DL: 0.01 $\mathrm{ppb}$ ) in the A.nilotica and A.leucophloea, indicating that they are safe

Table 1: Heavy metal analysis results of A.nilotica Linn and A.leucophloea Willd flowers

\begin{tabular}{cccc}
\hline HeavyMetal & Maximum & \multicolumn{2}{c}{ Observed value } \\
\cline { 3 - 4 } & Permissible Limit & A.nilotica & A.leucophloea \\
\hline Arsenic $(\mathrm{As})$ & $3 \mathrm{ppm}$ & $0.002 \mathrm{ppm}$ & $0.001 \mathrm{ppm}$ \\
Cadmium $(\mathrm{Cd})$ & $0.3 \mathrm{ppm}$ & $0.25 \mathrm{ppm}$ & $0.21 \mathrm{ppm}$ \\
Mercury & $1 \mathrm{ppm}$ & $0.12 \mathrm{ppm}$ & $0.08 \mathrm{ppm}$ \\
Lead $(\mathrm{Pb})$ & $10 \mathrm{ppm}$ & $0.16 \mathrm{ppm}$ & $0.10 \mathrm{ppm}$ \\
\hline
\end{tabular}

Table 2: Pesticide residue analysis results of A.nilotica Linn and A.leucophloea Willd flowers

\begin{tabular}{cccc}
\hline Pesticide & Detection Limit & A.nilotica & A.leucophloea \\
\hline Organo chlorine & $0.005 \mathrm{mg} / \mathrm{kg}$ & BDL & BDL \\
Organo phosphorus & $0.005 \mathrm{mg} / \mathrm{kg}$ & BDL & BDL \\
\hline
\end{tabular}




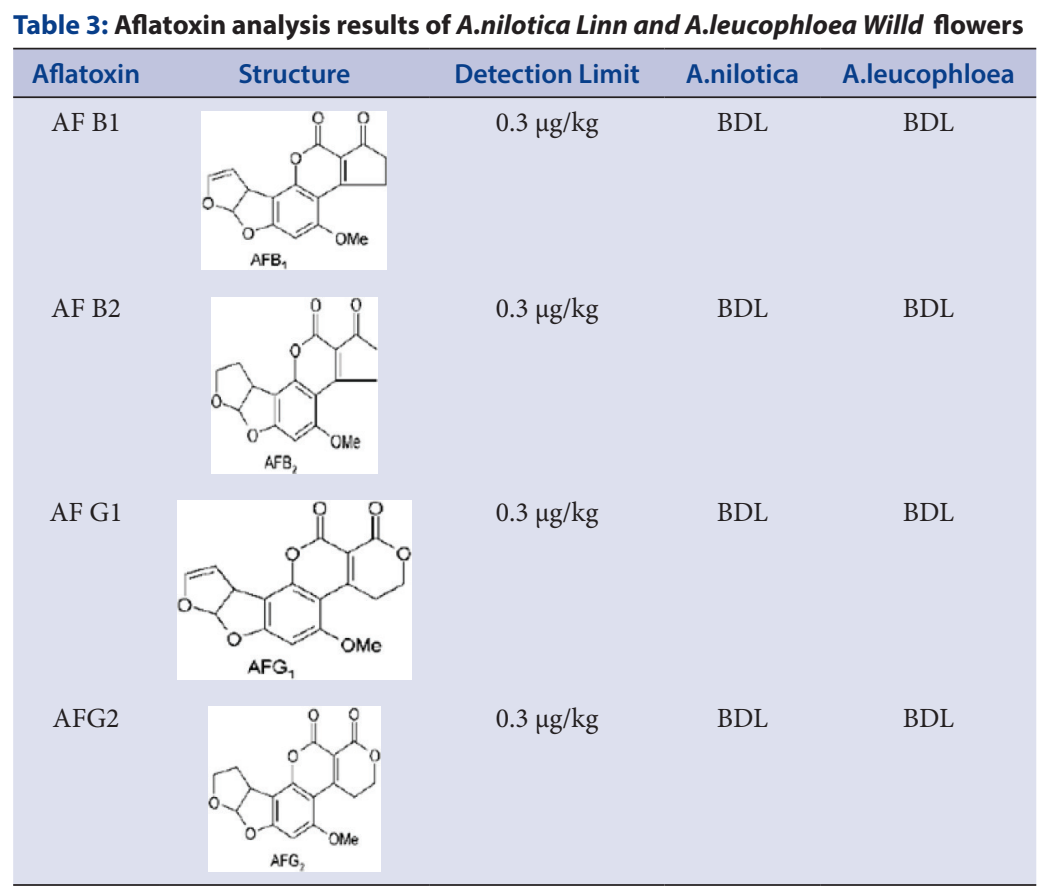

Table 4: Total microbial load results of A.nilotica Linn and A.leucophloea Willd flowers

\begin{tabular}{ccc}
\hline Parameters & A.nilotica & A.leucophloea \\
\hline Total Bacterial count & $3.3 \times 10^{3} \mathrm{cfu} / \mathrm{g}$ & $5.2 \times 10^{4} \mathrm{cfu} / \mathrm{g}$ \\
Total fungal count & $<10^{3} \mathrm{cfu} / \mathrm{g}$ & $3.3 \times 10^{2} \mathrm{cfu} / \mathrm{g}$ \\
Enterobacteriaceae & $<10 \mathrm{cfu} / \mathrm{g}$ & $<10 \mathrm{cfu} / \mathrm{g}$ \\
Salmonella & Absent & Absent \\
S. aureus & Absent & Absent \\
\hline
\end{tabular}

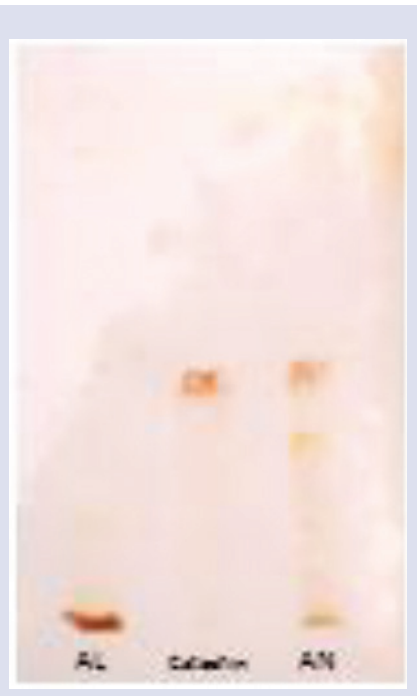

Figure 1: TLC of A.nilotica Linn and A.leucophloea Willd flowers

for their usage as drugs (Table 2). Analysis for the microbial load for the A. nilotica and A.leucophloea is found to be within the limit of WHO guidelines, indicating that they are free from pathogens and can be used as drugs (Table 4).

The TLC analysis reveals that the marker compound Catechin was found to be present in Acacia nilotica flower extract but catechin was found to be absent in Acacia leucophloea flowers (Figure. 1). It is interesting to note that in stem bark of Acacia leucophloea the catechin was absent. ${ }^{28}$

\section{CONCLUSION}

The flowers of Acacia nilotica and Acacia leucophloea exhibit a set of diagnostic characters, which will help to identify the drug in dried condition. It has been concluded from this study that estimation of heavy metals and pesticides residue, aflatoxin and total microbial load is highly essential for raw drugs or plant parts used for the preparation of single and compound formulation drugs. Plant-based traditional knowledge has become a recognized tool in search for new sources of drugs; it is clear that these herbal medicines will offer a platform for further research. So,concluding that both species (A.leucophloea and A. nilotica) can be distinguished on the basis of their secondary metabolites like catechin. Furthermore isolation of catechin is needed to explore its medicinal value in order to establish as a standard drug. Hence the periodic assessment is essential for quality assurance and safer use of herbal drugs.

\section{ACKNOWLEDGMENT}

We are thankful to the Director General, CCRAS,M/O AYUSH,GOI,New Delhi for the facilities provided.

\section{CONFLICT OF INTEREST}

We declare that we have no conflict of interest. 


\section{REFERENCES}

1. Chan K. Some aspects of toxic contaminants in herbal medicines. Chemosphere. 2003;52(9):1361-71.

2. Miraldi E, Giachetti D, Ferri S. Quality control of aromatic drugs reported in European Pharmacopoeia $3^{\text {rd }}$ edition. II Farmaco. 2001;56(5):365-71.

3. Tewary DK, Kumar V, Shanker A. Leaching of pesticides in herbal decoction. Chemical Health and Safety. 2004;11(4):25-9.

4. Sankararamakrishnan N, Sharma AK, Sanghi R. Organochlorine and organophosphorous pesticide residues in ground water and surface waters of Kanpur, Uttar Pradesh, India. Environment International. 2005;31(1):113-20.

5. Reddy SV, Kiran Mayi D, Uma Reddy M, Thirumala-Devi K, Reddy DV. Aflatoxins B1 in different grades of chillies (Capsicum annum L.) in India as determined by indirect competitive-ELISA. Food Additives and Contaminants. 2001;18(6):553-8.

6. IARC Working Group on the Evaluation of Carcinogenic Risks to Humans. Some naturally occurring substances: food items and constituents, heterocyclic aromatic amines and mycotoxins. World Health Organization, International Agency for Research on Cancer; 1993.

7. Groopman JD, Kensler W. Temporal patterns of aflatoxin albumin adducts in hepatitis B surface antigen-positive and antigen negative residents of Daxin Qidong County, People's Republic of China. Cancer Epidemiology Biomarkers and Prevention. 1996;5(4): 253-61.

8. Midio AF, Campos RR, Sabino M. Occurrence of aflatoxins B1, B2, G1 and G2 in cooked food components of whole meals marketed in fast food outlets of the city of Sao Paulo, SP, Brazil. Food Additives and Contaminants. 2001;18(5):445-8.

9. Feuell Aj. Aflatoxin in groundnuts. Part 9: Problems of detoxification. Tropical Science. 1996;8: 61-70.

10. Mudaliyar CS. Siddha Materia Medica. Part I, Chennai: Medicinal Plants division Department of Indian Medicine and Homeopathy. 2002;6:381-6.

11. Ravindrasharma. Medicinal plants of India-An encyclopedia. 2003;4.

12. Ahluwalia KS. Medicinal plants of Kerala-IV. Nagarjun. 1968;11:300-3.

13. Yoganarasimhan SN. Bhatt AV, Togunashi VS. Medicinal plants from Mysore district Karnataka. Indian Drugs Pharmaceut Ind. 1979;14:7-22.

14. Yoganarasimhan SN, Nair KV, Keshavamurthy KR, Govindaiah. Medico botany of Karnataka-3. Utilization of floristic wealth for the economic development of Kanakapura Taluk, Bangalore district. J Econ Tax Bot. 1982;6:97-108.

15. Kapoor SL, Kapoor LD. Medicinal plant wealth of the Karimnagar district of Andhra Pradesh. Bull Med Ethnobot Res.1980; 1: 120-144.

16. Sebastian MK, Bhandari MM. Medico-ethno botany of Mount Abu, Rajasthan, India.J Ethnopharmacol.1984a;12(12): 223-30.

17. Khan MA, Khan T, Ahmad Z. Barks used as source of medicine in Madhya Pradesh, India. Fitoterapia.1994;65:444-6.

18. Apparnantham T, Chelladurai V. Glimpses of folk medicines of Dharmapuri forest division, Tamilnadu. Ancient Sci Life. 1986;5:182-5.

19. Reddys SV, Kiran MD, Uma RM, Thirumala D, Reddy K, D.V.R. Aflatoxins B1 in different grades of chillies (Capsicum annum $\mathrm{L}$ ) in India as determined by indirect comp 2001; 12.

20. Selvanayagam ZE, Gnavanendhan SG, Balakrishna K, BhimaRao R, UsmanA S. Survey of medicinal plants with antisnake venom activity in Chengalpattu district, Tamilnadu, India. Fitoterapia. 1995;66(6):488-92

21. Hemadri K, Raj PV, Rao SS, Sharma CRR. Folklore claims from Andhra PradeshI. J Sci Res Plant Med. 1980;1:37-49.

22. Balaji RNS, Rajasekhar D, Chengal RD, Nagaraju N. Ethno-medicinal notes on some plants of tirumala hills for dental disorders. Ethnobotany. 1996;8: 88-91.

23. HorwitzW, Latimer GW, editors. Official Methods of Analysis of AOAC International. Chapter 10. 18 ${ }^{\text {th }}$ ed. Maryland: AOAC International;18-23.

24. Sahito SR, Kazi TG, Kazi GH, Jakhrani MA, Shaikh MS. Trace elements in two varieties of Indigeneous Medicinal Plant Catharanthus roseus. Sciences. $2001 ; 1,74-7$

25. Official Analytical Methods of the American Spice Trade Association. New Jersey: ASTA, Inc.; 1997; 4:149-52.

26. World Health Organization; Quality Control Methods for Medicinal Plant Materials. Geneva: WHO Publications; 1998; 10-31.

27. The Ayurvedic Pharmacopoeia of India, Part II, New Delhi: Ministry of Health and Family Welfare; 2008;168

28. Sulaiman CT, Gopalakrishnan K. Comparative phytochemical studies in Selected Acacia Species. International Journal of Pharmacy and Pharmaceutical Sciences. 2012:4(5):458-60

Cite this article : Leela V, Ilavarasan R. Phytochemical and Quality Assessment of Acacia nilotica Linn and Acacia leucophloea willd Flowers. Pharmacog J. 2017;9(6):721-4 